\title{
A Web-BASEd DSS FOr ERosion CONTROL StruCture PlanNing
}

\author{
Z. Tang, B. A. Engel, J. Choi，K. Sullivan, M. Sharif，K. J. Lim
}

\begin{abstract}
A Web-based decision support system called SEDSPEC (Sediment and Erosion Control Planning, Design and SPECification Information and Guidance Tool) (http://www.ecn.purdue.edu/runoff/sedspec) was developed for predicting small watershed peak runoff and designing hydrologic, sediment, and erosion control measures. The SEDSPEC system is comprised of a model, database, and user interface, which are typical components for a model-based Decision Support System (DSS). Two hydrologic models (the Rational Method and TR-55) simulate short-term peak runoff based on site-specific hydrologic soil groups and land uses. The hydrologic models estimate peak runoff using design storm data stored in associated databases. The DSS integrates WebGIS technology to help users estimate watershed boundaries and access a spatial database to obtain land use and hydrologic soil group data for the watershed. As the final output, SEDSPEC calculates dimensions and costs of hydrologic, sediment and erosion control structures based on users' specifications, and provide structure maintenance information. A case study is provided to demonstrate the use and functionality of the SEDSPEC DSS. This system can be an efficient tool to facilitate a decision-maker's design and planning procedures.
\end{abstract}

Keywords. Decision Support System (DSS), Web-based, WebGIS, Sediment and erosion control.

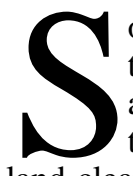

oil erosion is a complex, natural process driven by the action of water, wind, or glacial ice. It becomes a problem when human activities, such as agricultural practices, site construction, surface mining, land clearance, and urban expansion cause it to occur much faster than under natural conditions. Such human activities can accelerate water erosion by changing or removing vegetation (e.g. agricultural practices, site construction, surface mining, and land clearance) or increasing impervious surface (urban expansion). These alterations may increase peak flows of a storm event (Anderson, 1970; Moscrip and Montgomery, 1997; Corbett et al., 1997). The higher peak flows may consequently cause more erosion and eventually increase sediment carried off site. Surface runoff and eroded sediment pose a potential threat to the quality of the receiving water column by increasing turbidity and transporting nutrients and other contaminants such as heavy metals and pesticides. If contaminated sediments deposit in rivers and other water bodies, water-quality degradation may persist even when other pollution sources are controlled (Forman et al., 2000b).

Article was submitted for review in June 2003; approved for publication by the Information \& Electrical Technologies Division of ASAE in February 2004. Presented at the 2002 ASAE Annual Meeting as Paper No. 022124

The authors are Zhenxu Tang, ASAE Student Member, Research Assistant, Bernie A. Engel, Professor, Jin Yong Choi, Postdoctoral Fellow, Keith Sullivan, Research Assistant, Department of Agricultural and Biological Engineering, Purdue University, West Lafayette, Indiana Muhammed Sharif, Engineer, Construction Engineering Research Laboratories Division of the U.S. Army Corps of Engineers; and Kyoung Jae Lim, Postdoctoral Fellow, Department of Agricultural and Biological Engineering, Purdue University, West Lafayette, Indiana. Corresponding author: Bernie Engel, Department of Agricultural and Biological Engineering, Purdue University, 225 South University Street, West Lafayette, IN 47907-2093; phone: 765-494-1198; fax: 765-496-1115; e-mail: engelb@purdue.edu.
Accelerated erosion rates have both environmental and economic impacts that may result in extensive damage and expense. Consequently there is an increased demand for erosion control professionals to design and implement erosion control measures (Forman et al., 2000a). Significant effort has been directed toward developing models for hydraulic structure design and analysis. Some of the available software packages include SEDCAD, SURVCADD, SMS, UNET, and HEC-RAS. As examples, only the SEDCAD and HEC-RAS systems are briefly introduced here. SEDCAD (Sediment, Erosion and Discharge by Computer Aided Design) (Warner and Schwab, 1998) is an event-based, rainfall-runoff, erosion control, and predictive storm water and sediment model. The software can be used to design utilities such as channels, culverts, retention ponds, and plunge pools. A storm hydrograph and other rainfall data are used to design sediment basins that can handle maximum rainfall storage. SEDCAD cannot adequately design or evaluate complex and large hydraulic structures. HEC-RAS (Hydrologic Engineering Center's River Analysis System) (US ACE, 1995) is a widely accepted model developed by the U.S. Army Corps of Engineers for calculating water surface profiles for both steady and unsteady gradually varied flow. The system can model a full network of channels, a dendritic system, or a single river reach. The data required to perform the water surface elevation calculations include geometric data and steady or unsteady flow data depending on specific analysis (USACE, 2001). The HEC-RAS system has many advanced features, including evaluating the hydraulic effects of large stream channels and structures such as bridges. These structures cannot be modeled adequately with simple programs such as SEDCAD.

Models, such as SEDCAD, SURVCADD, SMS, UNET, and HEC-RAS, can provide assistance to water resource engineers, planners, and erosion control engineers for designing and implementing erosion control measures. However, the use procedure and data required by these tools 
are relatively complex, as these models are targeted to professionals. Users who don't possess extensive erosion control background and knowledge lack the ability to easily use these analytical tools to identify runoff and erosion problems and thereby plan corresponding structures. Professionals are also seeking screening tools to facilitate their design process.

The Sediment and Erosion Control Planning, Design and SPECification Information and Guidance Tool (SEDSPEC) was developed to fulfill the need for an easy-to-use, easy-to-access, and user-friendly decision support system (DSS) for hydrologic, sediment, and erosion control expressed by soil conservation planners, decision makers, and professionals. SEDSPEC predicts the peak runoff rate in the watershed using hydrologic models and helps to design hydrologic, erosion, and sediment control structures. SEDSPEC was built as a Web-accessible DSS integrated with interactive WebGIS technology to overcome challenges including data availability, ease of use, and access limitations. The objective of this article is to describe the framework of SEDSPEC in relation to the components of a DSS, its execution mechanism, and its capabilities to design site-specific hydrologic, erosion, and sediment control structures using a case study.

\section{BACKGROUND}

Shim et al. (2002) traced the development of the DSS concept, technology, and application since its inception in the 1960s and early 1970s until today. From a broad view, DSS is computer technology solution that can be used to support complex decision-making and problem solving. Classic DSS tool design is comprised of three components: (a) sophisticated database management capabilities with access to internal and external data, information, and knowledge; (b) powerful modeling functions accessed by a model management system; and (c) powerful, yet simple user interface designs that enable interactive queries, reporting, and graphing functions (Shim et al., 2002).

DSS have undergone significant evolution in the past three decades. The Internet is gaining a foothold in the area of DSS application. It was considered the center of activity in developing DSS at the beginning of the 21st century (Shim et al., 2002). A Web-based DSS is defined as a computerized system that delivers decision support information or decision support tools to a manager or business analyst using a Web browser such as Netscape Navigator or Internet Explorer (Power, 1999). Web-based DSS have created a major opportunity to deliver more quantitative and qualitative information to decision makers. Client-server architectures and networks permit information systems professionals to centralize and control information and yet easily distribute it in a timely manner to managers who need it (Power, 1998).

Typical water resources applications of DSS include water quality and quantity management at the river basin/watershed scale (Choi et al., 2001). With the advancement of Geographic Information Systems (GIS) technology, significant efforts to integrate GIS with hydrologic and soil erosion models have been undertaken (DeVantier and Feldman, 1993; Kopp, 1996; Yitayew et al., 1999; Tucker et al., 2000; Kim and Steenhuis, 2001) and implemented for decision support purposes (Johnston and Srivastava, 1999; Heaney et al., 2001) in dealing with hydrologic and water erosion problems. These efforts demonstrate the effectiveness of GIS integrated hydrologic models and DSS in watershed analyses.

WebGIS is an emerging technology for moving mapping and GIS functionality to the Internet. It holds the potential to make distributed geographic information available to a very large worldwide audience. Internet users will be able to access GIS applications from their browsers without purchasing proprietary GIS software. WebGIS makes it possible to add GIS functionality to network-based applications (Foote and Kirvan, 1997). One of the applications is that of Engel et al. (2003) in which WebGIS was integrated with a Web-based DSS for watershed hydrologic/water quality assessment. The WebGIS technique in the application supports Internet map browsing, online Web-based watershed delineation, and hydrologic spatial data extraction. WebGIS has several advantages over desktop GIS in terms of data resources, access by potential users, visualization and remote access, and some limitations imposed by network communication (Choi et al., 2001).

\section{WEB-BASED SEDSPEC DSS DESCRIPTION}

The SEDSPEC DSS can facilitate decision-making in designing hydrologic, erosion and sediment control structures while planning conservation in a watershed. Its implementation in the Internet enhances information delivery by expanding accessibility. The integration of WebGIS improves the effectiveness of the system by simplifying its use. The SEDSPEC system design and structures are described in the following sections.

SEDSPEC was designed based on the requirements of a typical DSS system. Figure1 presents the framework of the Web-based SEDSPEC DSS. It consists of the following components:

- Model: contains hydrologic models for predicting shortterm peak runoff and a knowledge base and design standards for recommending and designing erosion and hydrologic control structures;

- Database: stores precipitation data, spatial land use and soil group data needed for SEDSPEC operation;

- User interface: allows effective interaction between the user and the system;

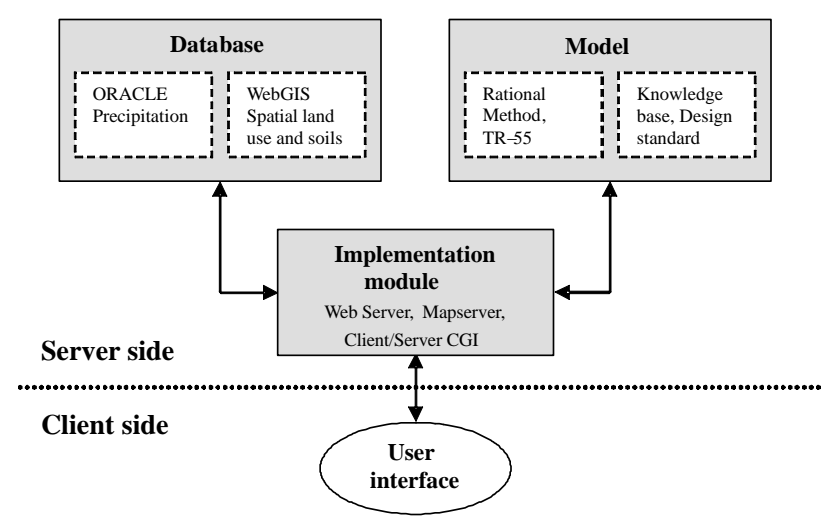

Figure 1. SEDSPEC Web-based DSS structure. 
- Implementation module: manages data distribution in the system and element integration and communication. It is the SEDSPEC architecture and networking design element.

The models and database are located on the server side. Users can utilize the models and GIS tools without purchasing and installing them on their local computers. Only an Internet-accessible computer is needed on the client side to access the user interface.

\section{MODEL}

An overview of the SEDSPEC input, output, and analysis process is depicted in figure 2 .

\section{Hydrologic Models}

Two well-documented hydrologic models, the Rational Method (Chow et al., 1988) and TR-55 (USDA-NRCS, 1986), are employed in SEDSPEC to predict short-term peak runoff. The Rational Method is a simple and easy-to-use method to predict design peak runoff for small watersheds up to $2.6 \mathrm{~km}^{2}$ (1 square mile). TR-55 estimates peak runoff in small watersheds up to $51.8 \mathrm{~km}^{2}$ (20 square miles) with emphasis on urban and urbanizing watersheds (USDANRCS, 1986). The Kirpich formula was employed to compute time of concentration (Kirpich, 1940) in the SEDSPEC Rational Method. In TR-55, the Soil Conservation Service (SCS) curve number method is used to calculate runoff depth, and the time of concentration is estimated from watershed lag time (USDA-NRCS, 1986).

The primary reason that SEDSPEC uses the Rational Method and TR-55 models is their readily available input data. Both models require only basic watershed parameters, including rainfall, hydrologic soil group, land use, maximum length of flow, and slope. Although the complicated runoff process is greatly simplified in these models, the Rational Method and TR-55 are probably the most widely used methods for design of storm sewers (Pilgrim, 1986; Linsley, 1986) and are capable of estimating runoff in the design of relatively inexpensive structures where the consequences of failure are limited. The use of quick and straightforward hydrologic models established the basis for SEDSPEC to be an easy-to-use tool.

\section{Recommendation and Design Criteria}

The process of selecting the correct structures to solve hydrologic and erosion problems can be difficult. SEDSPEC suggests structures based on site characteristics to help users narrow their choices. The knowledge-based recommendation function is implemented using a checklist method. The criteria used in SEDSPEC for recommending appropriate erosion control structures consider the site characteristics provided by the user's responses for a series of Yes/No questions regarding location, site size, slope, land use, vegetation quality, erosion level, and the structure maintenance and cost information. During the development of

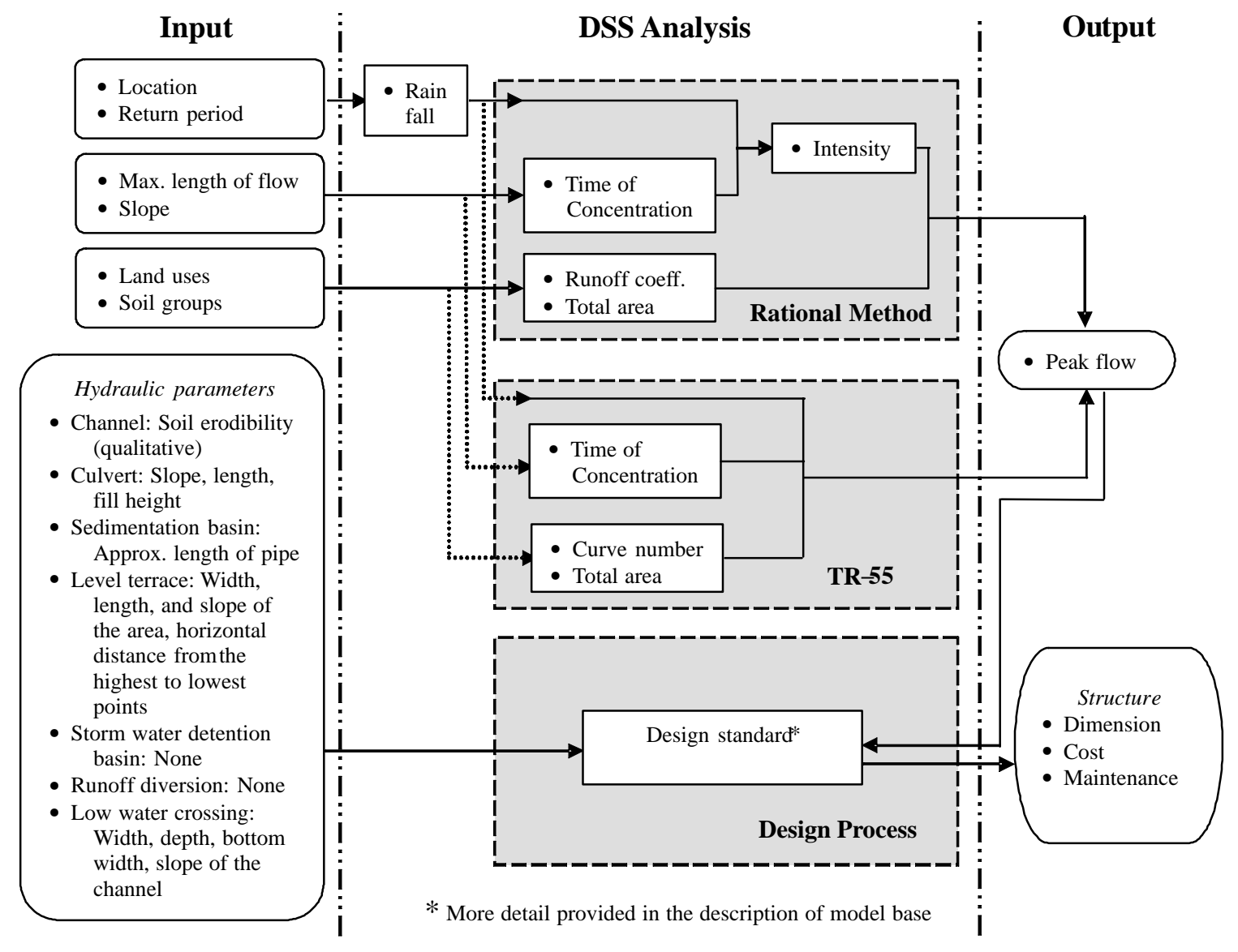

Figure 2. Overview of SEDSPEC input, output and analysis process. 
SEDSPEC, experts provided suitability criteria for each structure. The suitability properties of all the structures are considered and the most suitable structures are recommended in response to a user's description of the site.

SEDSPEC provides design, cost and maintenance information for common hydrologic and erosion control structures based on estimated peak runoff and site characteristics. Input hydraulic parameters for each structure are summarized in figure 2 . The computational methods for each design structure are briefly described next. Detailed calculation formulas are listed at the SEDSPEC Web site (http://www.ecn.purdue.edu/runoff/sedspec).

- Grass-lined channel: The method used to size grass-lined channels was adapted from Jarret (1995). Hydraulic radius is calculated using Manning's equation and maximum permissible velocity, which is determined based on the grass type, slope of the site, and soil erodibility. The depth and width are derived from hydraulic radius, peak runoff, and maximum permissible velocity. An iterative process guarantees that the ratio between channel width and depth is greater than 10 .

- Riprap-lined, concrete-lined, and open channels: The dimension of the channel is geometricly determined by depth of the channel computed using an iterative process, which assures that the channel capacity is between $100 \%$ and $110 \%$ of the peak flow. Manning's equation is used to compute channel capacity.

- Culvert: The diameter of the culvert is derived to accommodate peak flow. The calculation takes into account whether orifice conditions or pipe flow are present at the site.

- Sediment basin: The basin is assumed rectangular and its length is twice as long as its width. The dimensions are derived by computing the surface area of the basin using peak flow and the sediment storage volume (Smolen, 1988).

- Level terraces: Horizontal and vertical intervals are computed based on the location, slope and soil condition (Schwab et al., 1993). The terraces are designed to store runoff for a 10-year 24-hour event. Cut and fill are obtained from an iterative process. Subsurface tile drains are assumed to drain the terraces. The sizes of the tile drains are computed assuming plastic drain tubing and fixed spacing.

- Storm water detention basin: The basin is assumed to be rectangular and its length is twice as long as its width. The required storage capacity of a basin is derived based on the estimated peak flow of pre- and post-development conditions for a user-specified storm return period. The basin dimensions are determined for varied basin depths.

- Runoff diversion: SEDSPEC assumes a trapezoidal channel shape with 4:1 sideslopes. The computation method is the same as the method for calculating riprap-lined, concrete-lined, and open channels.

- Low water crossing: SEDSPEC returns flow velocities for various flow depths using Manning's equation based on the dimensions of the crossing provided by the user.

The total cost estimated for a designed structure includes two parts: (1) material costs and (2) soil excavating and hauling costs which are computed based on computed dimensions and unit cost data from the U.S. Army Construction Engineering Research Laboratory and RS Means (1997).
Users are cautioned not to build structures based solely on SEDSPEC calculations.

\section{Database \\ Precipitation Database}

The precipitation database in SEDSPEC includes three databases: the NOAA Technical Paper (TP-40) database (Hershfield, 1961), the Midwestern Climate Center (MCC) database (Huff and Angel, 1992), and the North Carolina erosion and sediment control planning and Design Manual (NCDM) database (Smolen, 1988). They all provide precipitation data for return periods of $1,2,5,10,25,50$, and 100 years. However, the areas that the three databases cover and the precipitation durations differ. TP-40 contains nationwide precipitation data for durations of $0.5,1,2,3,6$, 12 , and $24 \mathrm{~h}$. MCC considers more recent observed rainfall data than TP-40 and covers Midwestern states for durations of 5, 10, 15, and $30 \mathrm{~min} ; 1,2,3,6,8,12,18,24,48$, and $72 \mathrm{~h}$; and 5 and 10 days. NCDM includes data only for North Carolina with the same duration as the MCC database. The SEDSPEC user need only provide the location of interest (state and county) and desired return period to obtain precipitation data for SEDSPEC operation. The databases can also be used in other applications beyond SEDSPEC for retrieving precipitation data.

\section{WebGIS Spatial Database}

SEDSPEC is coupled with a Web-based watershed delineation tool powered by WebGIS technology that is supported by the MapServer software (University of Minnesota, 1996), an open source development environment. The Web-based watershed delineation tool enables users to estimate a watershed boundary, based on a graphically selected outlet point, and to query a spatial GIS containing STATSGO soil maps (1996) and USGS EROS land use maps (1992) for the delineated watershed. Hydrologic soil group and land use data can be obtained for the watershed of interest and are automatically supplied to the SEDSPEC data input form. Further details about this Web-based watershed delineation tool can be found in Engel et al. (2003).

The WebGIS spatial database currently provides partial input data for Illinois, Indiana, Ohio, Wisconsin, and Fort Bragg (Army base in North Carolina). For watersheds in these locations, users have options to use their own data or data served from the WebGIS spatial database. For watersheds in other locations, the user needs to provide their own data. Work is underway to provide the complete hydrologic data needed for SEDSPEC from WebGIS spatial databases and eventually expand the spatial data nationwide.

\section{USER INTERFACE}

The user interface is the only DSS component visible to the user. It transforms user queries and updates requests into appropriate sequences of commands to the other DSS components. The Web-based SEDSPEC interface facilitates information transformation between user and server, where the models and database reside, in the following ways: (a) serves as the front end for entering hydrologic parameters of watersheds and hydraulic parameters of hydrologic erosion control structures, (b) provides features for extracting information stored in the database and saving input/output for the user's application to the server, (c) displays and 
illustrates the design structures upon the user's specific request, and (d) provides instant help in terms of input parameters and system usage. Screenshots of the user interface are provided in the SEDSPEC implementation section.

\section{IMPLEMENTATION MODULE}

SEDSPEC was developed using the open source programming language Practical Extraction and Report Language (PERL) with the help of JavaScript and Server Side Includes (SSI) to handle formatting and error checking. The database and models are located on the server side. Data and model system management and computationally intensive portions of the applications are also conducted on the remote server. The only need on the client side is a Web browser, such as Netscape or Internet Explorer. Users interact with a Web graphical interface, which can dynamically build input files based on the user's specification. Input data is transmitted from the client to the server through Common Gateway Interface (CGI) programs.

Structured Query Language (SQL) is used to query the precipitation database in ORACLE relational table format. SQL queries are constructed during run-time based on the user-selected location. The spatial database for land use and hydrologic soil groups is managed by MapServer WebGIS software. With the user's input data and queried watershed and precipitation data from the database, the hydrologic models and design process are executed on the server using PERL programs. Results are returned to the Web browser by CGI and displayed in table or graph format.

\section{IMPLEMENTATION AND EVALUATION OF SEDSPEC DSS FUNCTIONALITIES}

The primary objective for building the SEDSPEC DSS is to facilitate potential users' analyses of runoff and erosion problems for their site of interest while planning. The analyses provide information (dimensions, costs, and maintenance information) about different types of runoff and erosion control structures based on the estimated short-term peak rate of runoff. In this section, the flow process through SEDSPEC DSS is introduced in terms of its DSS functionalities.

Runoff and erosion control structure design is the core function of SEDSPEC. Seven possible engineering practices including channels, culverts, sediment basins, level terraces, storm water detention basins, runoff diversions, and low water crossings can be designed in SEDSPEC. Grass-lined, riprap-lined, concrete-lined, and open channels comprise the channel structure option. The user starts the design by specifying the preferred structure(s) and continues to select the location (state and county) of interest. An option is provided for the user to choose a hydrologic model (TR-55 or the Rational Method) for computing peak runoff. Upon selecting a hydrologic model, the user is required to supply watershed parameters. Figure 3 is a screen example of the parameter input page for the Rational Method. A link for the STATSGO hydrologic soil group map is shown on this page based on the state specified by the user. The user also needs to provide hydraulic parameters for the specified structure, if any are required (fig. 2). A resultant channel design example is shown in figure 4 . The structure dimensions are also provided. Cost, maintenance, and technical information are displayed from the output screen by selecting appropriate buttons. The user has the option to save the application input data and to create a report summarizing the input and output of the user's analysis, which can be retrieved by the user in the future.

The integration of WebGIS improves the effectiveness of SEDSPEC by simplifying the process of supplying watershed parameters. It eliminates the need to spend significant time finding and entering the necessary data. The incorporation of WebGIS empowers the user to explore geographically. By only identifying the watershed outlet, users can obtain an estimated watershed boundary and the necessary watershed hydrologic parameters needed for SEDSPEC execution by querying the spatial WebGIS database. An example of the WebGIS interface is presented in figure 5.

The performance of the SEDSPEC system was evaluated in two ways. First, example structure design problems in the textbooks by Schwab et al. (1993) and Jarret (1995) were used for evaluation purposes. The input data for SEDSPEC was acquired from the sample problems and the outputs from SEDSPEC were compared to the results from the design in the textbooks. The structure design results from SEDSPEC matched the solutions in the textbooks. Second, three erosion

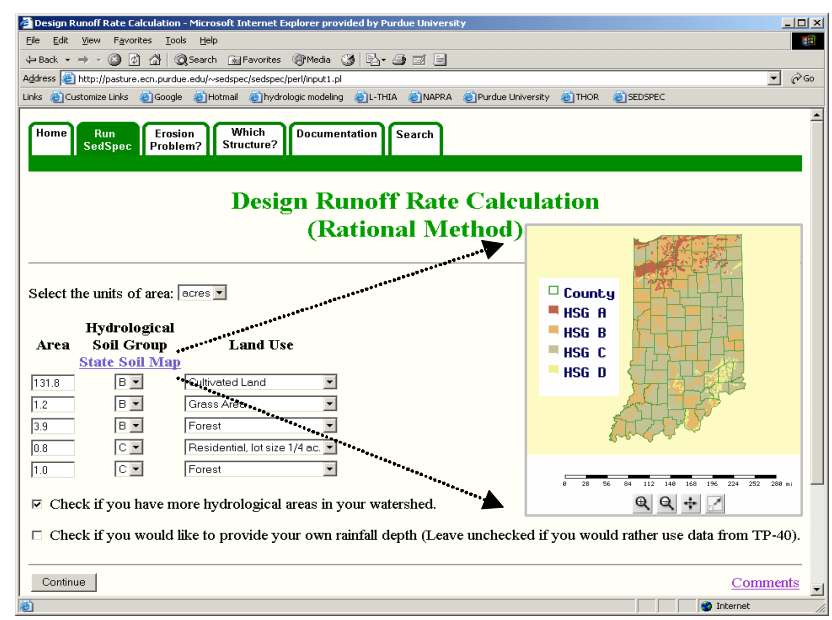

Figure 3. Rational Method input parameters screenshot.

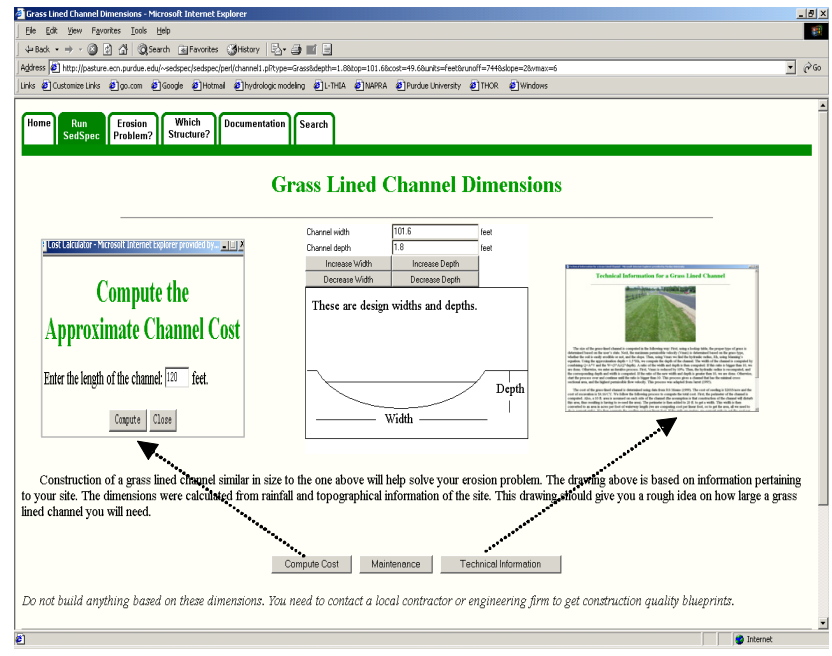

Figure 4. Channel design output in SEDSPEC. 


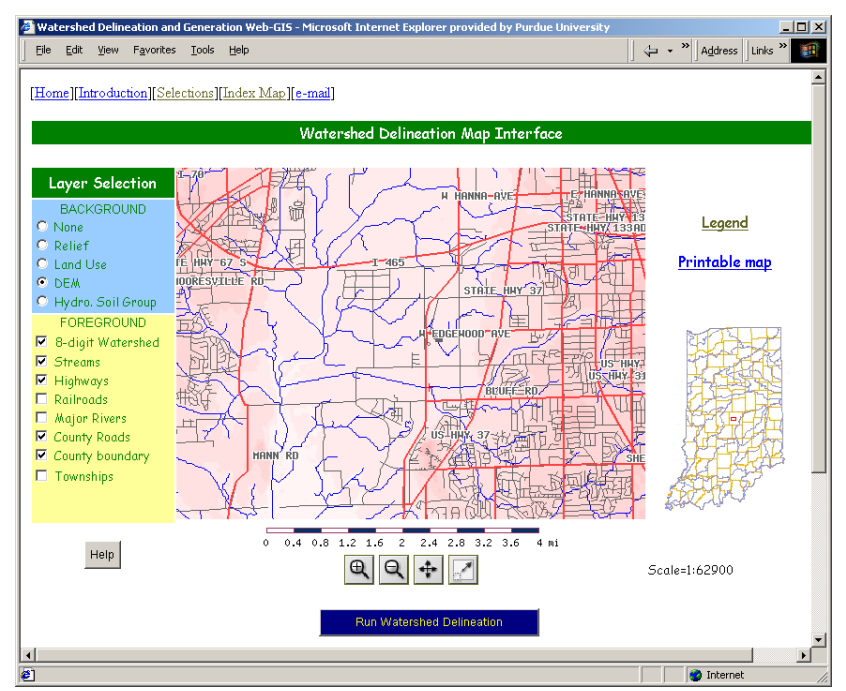

Figure 5. WebGIS watershed delineation interface.

and hydrology BMP experts other than the authors contributed to the system evaluation process. They examined the theoretical background and coding of all components of the system, including models, databases, interfaces, and their implementation. They also examined the output of the SEDSPEC application for numerous structure designs. The expert evaluation included all structures that the system designs. The results verified that the SEDSPEC system can be an efficient tool to facilitate a decision-maker's design and planning procedures.

\section{A SEDSPEC DSS APPLICATION Case STUdy}

The SEDSPEC DSS was applied to two watersheds to demonstrate how it can be used to facilitate planning of hydrologic and erosion control structure designs. To demonstrate the options for users to choose a hydrologic model and the methods to obtain hydrologic input data, the TR-55 hydrologic model with user defined watershed data was used in Watershed I and the Rational Method hydrologic model integrated with the watershed delineation tool to provide land use and soil data was used in Watershed II.

\section{STUDY Areas}

Watershed I is located in the northwest section of Indianapolis, Indiana with an area of 46.1 ha. Diverse land uses are present in the watershed, ranging from nonurban natural grass and agricultural areas to urban high density (HD) residential, low density (LD) residential, and commercial categories. Urban categories are the predominant land use and account for more than $80 \%$ of the total area. The extensive urbanization has created vast impervious areas, which resulted in the need to construct runoff and erosion control structures in order to overcome the challenge of the increased runoff.

Watershed II is located in Clinton County in north central Indiana with an area of 55.4 ha. The land use is comprised of nonurban categories, including agricultural, grass/pasture, and forest areas. Agriculture is the predominant land use in the watershed and accounts for $96 \%$ of the total area.

\section{DATA USED}

In Watershed I, land use and hydrologic soil group data are needed for SEDSPEC DSS application. Hydrologic soil group is a group of soils having similar runoff potential under similar storm and cover conditions. The soils in the United States are generally placed into four groups: A, B, C, and D (USDA-NRCS, 2002). Hydrologic soil group data were obtained from Soil Survey Geographic (SSURGO) maps provided by USDA NRCS. Hydrologic soil groups B and C are present in the watershed. Land use data from the early 1990s from the USGS EROS data center with 30- $\times 30-\mathrm{m}$ grid size were used. They were originally interpreted from Landsat TM images. The watershed was delineated from a digital elevation model (DEM) using a desktop GIS tool. The GIS tool was also used to process hydrologic soil group and land use data for the watershed.

In Watershed II, land use and hydrologic soil group data were derived from the WebGIS watershed delineation tool. All areas are group B soil.

Land uses and areas by the soil types within watersheds I and II are presented in table 1 . In both watersheds, the basin hydraulic length and average slope were measured using a DEM and the delineated watershed map (table 2).

\section{RESUltS}

Watershed I is a typical urbanized area, as urban areas comprise $80 \%$ of its overall land uses. A runoff diversion structure was selected for the watershed I design, and channels were considered for watershed II. The dimensions for the runoff diversion were computed for seven rainfall return periods, ranging from 1 to 100 years. Channels were designed for a return period of 10 years. Precipitation from the MCC database was used for both watersheds.

For designing runoff diversions in Watershed I, SEDSPEC assumed a trapezoidal channel shape with 4:1 side slopes and calculated the dimensions of the runoff diversion based on peak flow returned by the TR-55 hydrologic model. For

\begin{tabular}{|c|c|c|c|c|}
\hline \multicolumn{3}{|l|}{ Watershed I } & \multicolumn{2}{|c|}{ Watershed II } \\
\hline \multirow[b]{2}{*}{ Land Use } & \multicolumn{2}{|c|}{$\begin{array}{c}\text { Areas by } \\
\text { Hydrologic } \\
\text { Soil Group } \\
\text { (ha) }\end{array}$} & \multirow[b]{2}{*}{ Land Use } & \multirow{2}{*}{$\begin{array}{c}\text { Areas by } \\
\text { Hydrologic } \\
\text { Soil Group } \\
\text { (ha) } \\
\text { B }\end{array}$} \\
\hline & $\mathrm{B}$ & $\mathrm{C}$ & & \\
\hline Low density residential & 0.5 & 1.0 & Cultivated & 53.3 \\
\hline High density residential & 0.1 & 0.5 & Grass/pasture & 0.5 \\
\hline $\begin{array}{l}\text { Commercial/industrial/ } \\
\text { transportation }\end{array}$ & 11.2 & 24.6 & Forest & 1.6 \\
\hline Urban/recreational grasses & 1.4 & 2.2 & & \\
\hline Pasture/hay & 1.5 & 2.3 & & \\
\hline Row crop & 0.4 & 0.4 & & \\
\hline Total & 15.1 & 31.0 & Total & 55.4 \\
\hline
\end{tabular}

Table 2. Hydraulic length and average slope of watersheds I and II.

\begin{tabular}{lcc}
\hline Parameters & Watershed I & Watershed II \\
\hline Hydraulic length $(\mathrm{m})$ & 860 & 1050 \\
Average slope $(\%)$ & 0.9 & 2.1 \\
\hline
\end{tabular}


designing channels in Watershed II, riprap, concrete, and open channels are assumed to be trapezodial in shape with 1:1 sideslopes. The grass-lined channel is assumed to be parabolic. The channel dimensions were calculated using peak flow returned by the Rational Method. Unit costs for constructing the channels were computed as well, and the total cost can be calculated by specifying the desired channel length.

Tables 3 and 4 summarize the output from SEDSPEC for both watersheds. Watershed I is in a flat area with an average slope of $0.9 \%$. Therefore, it has low potential for peak discharge. However, the urbanization of the area increases the runoff peak and therefore increases the dimension of the runoff diversion structure. The peak rates of runoff from watershed I range from $2.6 \mathrm{~m}^{3} / \mathrm{s}$ for a 1-year return period event to $7.6 \mathrm{~m}^{3} / \mathrm{s}$ for a $100-$ year return period event. In watershed II, the peak rate of runoff from the low runoff potential land use practice (agricultural) for the 10-year return period event is $2.9 \mathrm{~m}^{3} / \mathrm{s}$.

The SEDSPEC output helps users to estimate roughly the dimensions and costs of the designed structures to facilitate the decision-making process. Designing by qualified personnel is recommended before building structures.

\section{CONCLUSION}

SEDSPEC, a Web-based DSS prototype, was developed to facilitate decision making in identifying hydrologic and erosion problems and designing control structures while planning conservation practices in small watersheds. The Web-based and GIS integrated SEDSPEC DSS has several advantages compared to the classical desktop DSS. First, its implementation in the WWW enhances the information delivery by expanding accessibility. Second, it requires minimal resources from users, mainly an Internet-accessible computer. Users can utilize the models and GIS tools without purchasing and installing them on their local computers. The models, the GIS package, and the extensive database all reside on the server. Computationally intensive portions of

Table 3. Runoff diversion dimensions designed by SEDSPEC for watershed $I$.

\begin{tabular}{|c|c|c|c|c|c|c|}
\hline \multirow{2}{*}{$\begin{array}{l}\text { Return } \\
\text { Period } \\
\text { (year) }\end{array}$} & \multirow[b]{2}{*}{$\begin{array}{l}\text { Rainfall } \\
(\mathrm{mm})\end{array}$} & \multirow{2}{*}{$\begin{array}{c}\text { Peak } \\
\text { Discharge } \\
\left(\mathrm{m}^{3} / \mathrm{s}\right)\end{array}$} & \multicolumn{3}{|c|}{ Dimension (m) } & \multirow{2}{*}{$\begin{array}{l}\text { Unit } \\
\text { Cost } \\
(\$ / \mathrm{m})\end{array}$} \\
\hline & & & $\begin{array}{l}\text { Channel } \\
\text { Width }\end{array}$ & $\begin{array}{l}\text { Bottom } \\
\text { Width }\end{array}$ & Depth & \\
\hline 1 & 65.0 & 2.6 & 2.9 & 0.3 & 1.3 & 11.5 \\
\hline 2 & 74.4 & 3.2 & 3.1 & 0.3 & 1.4 & 13.1 \\
\hline 5 & 94.7 & 4.4 & 3.5 & 0.4 & 1.6 & 16.2 \\
\hline 10 & 106.9 & 5.2 & 3.7 & 0.4 & 1.6 & 18.1 \\
\hline 25 & 120.7 & 6.0 & 3.9 & 0.4 & 1.7 & 20.2 \\
\hline 50 & 135.9 & 6.9 & 4.1 & 0.4 & 1.8 & 22.4 \\
\hline 100 & 147.3 & 7.6 & 4.2 & 0.4 & 1.9 & 24.0 \\
\hline
\end{tabular}

Table 4. Channel dimensions designed by SEDSPEC for watershed II.

\begin{tabular}{|c|c|c|c|c|c|c|c|}
\hline \multirow[b]{2}{*}{$\begin{array}{l}\text { Channel } \\
\text { Type }\end{array}$} & \multicolumn{3}{|c|}{ Flow Dimension (m) } & \multicolumn{3}{|c|}{ Design Dimension (m) } & \multirow{2}{*}{$\begin{array}{c}\text { Unit } \\
\text { cost } \\
(\$ / \mathrm{m})\end{array}$} \\
\hline & Depth & $\begin{array}{c}\text { Top } \\
\text { Width }\end{array}$ & $\begin{array}{l}\text { Bottom } \\
\text { Width }\end{array}$ & Depth & $\begin{array}{c}\text { Top } \\
\text { Width }\end{array}$ & $\begin{array}{l}\text { Bottom } \\
\text { Width }\end{array}$ & \\
\hline Riprap & 0.9 & 2.7 & 0.8 & 1.0 & 2.9 & 2.6 & 56.2 \\
\hline Concrete & 0.6 & 1.8 & 0.5 & 0.7 & 2.0 & 1.7 & 72.6 \\
\hline Open & 0.7 & 1.9 & 0.6 & 0.8 & 2.1 & 1.9 & 5.5 \\
\hline Grass & 0.4 & 6.9 & & 0.6 & 8.8 & & 27.9 \\
\hline
\end{tabular}

the applications are run on the server. Third, the integration of WebGIS improved the effectiveness of the SEDSPEC DSS by simplifying the process of providing watershed parameters.

SEDSPEC is a simple Web-based DSS for hydrologic, sediment, and erosion control planning. It requires only readily available hydrologic and hydraulic parameters to realize similar functions as more complicated models. The ease of use expands its benefits to not only professionals but also occasional users. Incorporating a precipitation database, the hydrologic models estimate peak runoff using design storms. Structure dimensions are determined based on the peak rate of runoff output by the models. The integrated WebGIS technologies enable users to estimate watershed boundaries and make use of a spatial database to obtain land use and hydrologic soil group data for the watershed.

In this article, a brief introduction of a typical Web-based DSS was given and the DSS components in SEDSPEC were described. A case study demonstrated how SEDSPEC can be used to facilitate the preliminary design of runoff and erosion control structures while planning. SEDSPEC is an interactive Web tool to help prevent runoff and erosion problems and eventually achieve sustainable development of the environment.

\section{REFERENCES}

Andersen, D. G. 1970. Effects of urban development of floods in Northern Virginia. U.S. Geological Survey Water Supply Paper 2001-C: 26.

Choi, J., B. A. Engel, S. Pandey, and J. Harbor. 2001. Web-based decision support system for evaluation of hydrological impact of urban sprawl. ASAE Paper No. 012026. St. Joseph, Mich.: ASAE.

Chow, V. T., D. R. Maidment, and L. W. Mays. 1988. Applied Hydrology International. New York: McGraw-Hill Book Company.

Corbett, C. W., M. Wahl, D. Porter, D. Edwards, and C. Moise. 1997. Nonpoint source runoff modeling: a comparison of a forested watershed and an urban watershed on the South Carolina coast. J. of Experimental Marine Biology and Ecology 213(1): 133-149.

DeVantier, B. A., and A. D. Feldman. 1993. Review of GIS applications in hydrologic modeling. J. of Water Resources Planning and Management 119(2): 246-261.

Engel, B. A., J. Choi, J. Harbor, and S. Pandey. 2003. Web-based DSS for hydrologic impact evaluation of small watershed land use changes. Computers and Electronics in Agriculture 39(3): 241-249.

Foote, K. E., and A. P. Kirvan. 1997. WebGIS, NCGIA Core Curriculum in GIScience. Available at: www.ncgia.ucsb. edu/giscc/units/u133/u133.html. Accessed 5 April 2002.

Forman, S. M., D. T. Williams, and I. M. Thomas. 2000a. Use of GIS, geo-based programs, and computer models for watershed site analyses-part 1. Erosion Control 7(6): 58-66.

Forman, S. M., M. J. Teal, D. T. Williams, L. R. Kreymborg, and C. M. Burnett. 2000b. Use of GIS, geo-based programs, and computer models for watershed site analyses-part 2. Erosion Control 7(7): 68-75.

Heaney, J. P., D. Sample, and L. Wright, 2001. Geographical information systems. Decision support systems and urban stormwater management. EPA. Available at: www.epa.gov/ednnrmrl/reports/NEWGISRE/CoverPage.pdf. Accessed 10 Dec. 2002. 
Hershfield, D. M. 1961. Rainfall frequency atlas of the united states for durations from 30 minutes to 24 hours and return periods from 1 to 100 years. Technical paper No. 40. Washington, D.C.: USDA Engineering Division, Soil and Water Service.

Huff, F. A., and J. R. Angel. 1992. MCC research report 92-03. Bulletin 71. Rainfall frequency atlas of the Midwest. Midwestern Climate Center and Illinois State Water Survey.

Jarret, A. R. 1995. Water Management. Dubuque, Iowa: Kendall/Hunt Publishing Co.

Johnston, D. M., and A. Srivastava. 1999. Decision support systems for design and planning: the development of HydroPEDDS (Hydrologic Performance Evaluation and Design Decision Support) system for urban watershed planning. Sixth International Conference on Computers in Urban Planning and Urban Management (CUPUMS '99). Venice, Italy.

Kim, S. J., and T. S. Steenhuis. 2001. GRIEROM: Grid-based variable source area soil-water erosion and deposition model. Transactions of the ASAE 44(4): 853-862.

Kirpich, Z. P. 1940. Time of concentration of small agricultural watersheds. Civil Eng. 10(6): 362.

Kopp, S. M. 1996. Linking GIS and hydrologic models: where have we been, where are we going? In HydroGIS '96: Application of Geographic Information Systems in Hydrology and Water Resources Management, eds. K. Kovar and H. P. Nachtnebel, 133-139. Wallingford, UK: IAHS Press.

Linsley, R. K. 1986. Flood estimates: How good are they? Water Resourcs Res. 22(9): 159S-164S.

Moscrip, A. L., and D. R. Montgomery. 1997. Urbanization flood, frequency and salmon abundance in Puget Lowlan Streams. J. of the American Water Resources Association 33(6): 1289-1297.

Pilgrim, D. H. 1986. Bridging the gap between flood research and design practice. Water Resources Res. 22(9): 165S-176S.

Power, D. J. 1998. Web-based decision support systems. The on-line executive journal for data-intensive decision support, 2(34) Available at: www.hpcwire.com/dsstar/ 98/0407/980407.html. Accessed 9 Dec. 2002.

Power, D. J. 1999. Decision support system glossary. DSS Resource. Available at: www.dssresources.com/glossary/. Accessed 9 Dec. 2002.
RS Means. 1997. RS Means Heavy Construction Cost Data. Kingston, Mass.: RS Means Company.

Schwab, G. O., D. D. Fangmeier, W. J. Elliot, and R. K. Frevert. 1993. Soil and Water Conservation Engineering, 4th ed. New York: John Wiley and Sons.

Shim, J. P., M. Warkentin, J. F. Courtney, D. J. Power, R. Sharda, and C. Carlsson. 2002. Past, present, and future of decision support technology. Decision Support Systems 33: 111-126.

Smolen, M. D. ed. 1988. Erosion and sediment control planning and design manual. Raleigh, North Carolina: North Carolina Sedimentation Control Commission, North Carolina DEHNR, and the North Carolina Cooperative Extension Service.

STATSGO. 1996. Soil maps. Available at: www.essc.psu.edu/soil_info/index.cgi?soil_data\&statsgo. Accessed 6 Dec. 2002.

Tucker, M. A., D. L. Thomas, D. D. Bosch, and G. Vellidis. 2000. GIS-based coupling of GLEAM and REMM hydrology: I. development and sensitivity. Transactions of the ASAE 43(6): $1535-1544$.

University of Minnesota. 1996. Mapserver. Available at: mapserver.gis.umn.edu/. Accessed 1 Dec. 2002.

USACE (Army Corps of Engineers). 1995. HEC-RAS Users Manual. Davis, Calif.: Hydrologic Engineering Center.

USACE (Army Corps of Engineers). 2001. HEC-RAS river analysis system. Hydraulic reference manual (version 3). Davis, Calif.: Hydrologic Engineering Center.

USDA-NRCS. 1986. Urban hydrology for small watersheds, Technical Release 55. USDA Natural Resources conservation service.

USDA-NRCS. 2002. National soil survey handbook, title 430-VI. Available at: http://soils.usda.gov/technical/handbook/. Accessed 26 Dec. 2002.

USGS. 1992. Land cover maps. Available at: edc.usgs.gov/products/landcoverhtml. Accessed 5 Nov. 2002.

Warner, C. R., and P. Schwab. 1998. SEDCAD 4 for Windows 95/98 \& NT, Design Manual and User's Guide. Ames, Iowa: Civil Software Design.

Yitayew, M., S. J. Pokrzywka, and K. G. Renard. 1999. Using GIS for facilitating erosion estimation. Applied Engineering in Agriculture 15(4): 295-301. 